\title{
DAS ORIGENS DA OCUPAÇÃO DA ESCOLA: O CASO DO MST ${ }^{1}$
}

\section{ON THE ORIGINS OF SCHOOL OCCUPATIONS: THE CASE OF THE LANDLESS RURAL WORKERS MOVEMENT - MST}

\author{
MARTINS, Fernando José ${ }^{2}$
}

\section{RESUMO}

A onda de ocupações das escolas que tomaram o Brasil em 2015 e amplamente em 2016 evidenciaram o fenômeno para os mais diferentes públicos. Ocorre que tal prática já é usada e localizada historicamente em outros espaços e movimentos, inclusive no que tange à escola. $\mathrm{O}$ que se quer no presente artigo é evidenciar a ocupação da escola no interior da prática do Movimento dos Trabalhadores Rurais Sem Terra - MST, e assim destacar que muitos contornos comuns da ocupação da escola, estão presentes em experiências, que podem parecer distintas, porém, partilham de um processo de formação política unificado.

Palavras-Chave: Ocupação; MST; Democracia.

\section{ABSTRACT}

The occupations of schools throughout Brazil in 2015, and more so in 2016, highlighted this phenomenon to a diversified public. This practice, however, is already used and has been historically located in other spaces and movements, including schools. This article approaches the occupation of schools in the context of the Landless Rural Workers Movement - MST - and emphasizing that many common aspects of school occupation are present in experiences that may seem distinct, but share a unified political development process.

KEYWORDS: Occupation; MST; Democracy.

\section{INTRODUÇÃO}

O presente artigo vai centrar-se na categoria ocupação da escola (MARTINS, 2011) a partir da prática de um movimento social, o MST. A primeira vista, pode parecer que há uma distinção entre a categoria no MST e nas ocupações realizadas nas escolas brasileiras nos últimos anos, principalmente pelos secundaristas. Há elementos específicos em cada ação, relações históricas distintas, uma vez que a ação dos secundaristas já foi empreendida em outras realidades, como no

\footnotetext{
${ }^{1}$ Artigo derivado da pesquisa de doutorado do autor, realizada junto ao programa de pós-graduação em Educação da UFRGS - Universidade Federal do Rio Grande do Sul, publicado no formado de livro (Martins, 2011) indicado nas referências.

2 Professor do Centro de Educação, Letras e Saúde da Universidade Estadual do Oeste do Paraná Unioeste, campus de Foz do Iguaçu. Docente do Programa de Pós-Graduação Sociedade, Cultura e Fronteiras e líder do Grupo de Pesquisa Estado, Sociedade, Trabalho e Educação - GPESTE. Mestre e doutor em Educação. e-mail: fernandopedagogia2000@yahoo.com.br
} 
movimento estudantil chileno. Ocorre que dois elementos necessitam ser destacados: 1) no caso brasileiro, a ocupação advinda do campesinato é marcante para todos os movimentos sociais, sem exceção. 2) o que será evidenciado no conjunto do artigo: a prática da ocupação da escola, enquanto categoria, contém elementos formativos comuns, desde as relações pedagógicas horizontais e autoorganizadas, até a formação humana em sentido omnilateral, que são percebidas em ambas situações.

Feita tal observação, é necessário ressaltar que não se trata de uma exposição comparada. Vão se evidenciar, no artigo, elementos conceituais e até históricos da ocupação da escola na prática do MST. Para tanto, inicialmente, localiza-se a categoria no conjunto das ações campesinas de luta pela terra; na sequência, a ocupação é evidenciada na prática educativa e na escola, a partir de documentos e sistematizações ligadas ao movimento.

\section{DA ORIGEM CAMPESINA}

A fixação na terra para fins de trabalho é uma premissa presente, há tempos, nas práticas de ocupação no meio camponês, mesmo que informalmente, mesmo sem conotação política. O modo de produção capitalista, quando atribui o caráter mercantil da terra, vai intensificar os debates sobre posse, propriedade privada e intensificar os conflitos sobre a questão agrária. É dessa mutação histórica e social que tem origem também os movimentos de luta pela terra, inclusive o MST, e esse movimento detém uma perspectiva social abrangente, insere questões como a agrária em uma dimensão social integral, somando o debate da terra, com o da educação, por exemplo.

A ideia de ocupação da escola se vincula a uma estratégia política que o movimento utiliza para tensionar o Estado no cumprimento da reforma agrária. Uma vez que a legislação brasileira estabelece, em sua Carta maior, no artigo 184, que: "Compete à União desapropriar por interesse social, para fins de reforma agrária, o imóvel rural que não esteja cumprindo sua função social (...)" e que a prática da desapropriação, ou seja, a legislação não era observada na realidade brasileira, baseada no latifúndio improdutivo, o MST se utiliza da estratégia política de ocupar as terras que "não cumprem sua função social".

Vale ressaltar que tal estratégia não é exclusiva do MST. É uma prática comum no campesinato brasileiro. Segundo Bernardo Mançano Fernandes (2000, p.281), "a ocupação é um processo socioespacial e político complexo que precisa ser compreendido como forma de luta popular de resistência do campesinato, para sua recriação e criação". Porém, é com o MST que esse processo ganha visibilidade social e também passa a integrar a identidade desse movimento social.

Além das práticas cotidianas de pressão, amplamente divulgadas pelos meios de comunicação social (que visam a criminalizar a "invasão" de terras), também, estrategicamente, a ocupação insere-se na dinâmica do Movimento. Em seu $5^{0}$ 
Encontro Nacional, realizado em Sumaré (fevereiro e março de 1989), além de formatado seu primeiro plano nacional, o MST assume o tema do encontro "Ocupar, resistir e produzir" também como lógica de luta. Mas do que isso, tal categoria, a ocupação, torna-se um elemento articulador de uma série de intencionalidades. Além de mecanismo de enfrentamento social, condensa também uma perspectiva de projeto de sociedade, uma concepção de classe e um posicionamento identitário. Nesse sentido, o fundamento da categoria ocupação está vinculado ao projeto de classe trabalhadora, um projeto emancipatório:

Portanto, a luta pela terra é uma luta constante contra o capital. É uma luta contra a exploração. E a ocupação é uma ação que os trabalhadores sem-terra desenvolvem lutando contra a exclusão causada pelos capitalistas e ou pelos proprietários de terra. A ocupação é, portanto, uma forma de materialização da luta de classes (FERNANDES, 2000, p.280).

Assim, quer-se destacar que a ocupação se insere em um processo social amplo, no presente caso. Parte do meio campesino, contudo, no interior do MST, envolve-se no contexto social amplo e é uma ferramenta formativa, por isso, a escola não vai passar despercebida. Em síntese, a totalidade é uma característica presente na categoria ocupação.

\section{OCUPAÇÃO, EDUCAÇÃO E ESCOLA}

Ao buscar a utilização dessa categoria no âmbito educacional (Ocupar, resistir e produzir também na educação ${ }^{3}$ !) igualmente lança mão da utilização de seus elementos constitutivos, como as categorias de classe, emancipação, entre outras. No entanto, há algumas particularidades que se assumem quando se trata da ocupação à escola: a realidade escolar que atende as camadas populares, principalmente os integrantes do MST, integra o sistema estatal de educação, geralmente em âmbito municipal e estadual; conta com corpo docente e técnico de pessoas internas e externas ao MST; recebe alunos também de comunidades externas; enfim, constitui-se de escolas inseridas no sistema regular de ensino público. No que diz respeito especificamente à escola pública, remeter-se à participação popular é referir-se à classe trabalhadora, portanto, "a transformação dessa escola passa necessariamente por sua apropriação por parte das camadas trabalhadoras" (PARO, 1997, p.10).

Esse princípio é essencial para a definição da categoria ocupação da escola. Contudo, mesmo que seja uma prática localizada no interior de um movimento social

\footnotetext{
${ }^{3}$ Lema que aparece em vários documentos do setor Educação do MST, cf. o Dossiê MST-Escola (MST, 2005).
} 
específico - o MST - é mister salientar que a categoria a ser desenvolvida extrapola esses limites. Para nós, é tida como possibilidade a todas as esferas do sistema educacional. $\mathrm{E}$, mesmo em esferas mais amplas de sua construção, pode-se perceber tal fato - a própria Educação do Campo - como um processo de ocupação que se consolida no sistema educacional nacional.

Ao abordar a temática, é perceptível que essa não seja uma concepção hegemônica. A educação do campo está se forjando e ganhando espaços no debate educacional, legal e científico. Essa construção coletiva tem a inserção, por vezes, efetuada pelos movimentos sociais, mas, de maneira geral, pelos sujeitos do campo. Dessa forma, a educação do campo ocupa espaço de debate educacional em nível nacional. Isso é um processo de ocupação da escola. Tal processo se materializa em diversas instâncias: no plano legal, com o estabelecimento das Diretrizes Operacionais para Educação Básica nas Escolas do Campo e, principalmente, com seu conteúdo; no plano político, com a contenção do processo de extinção das escolas rurais, sua reinserção no debate educacional e na estrutura estatal, e, principalmente, no plano identitário, com a promoção do debate sobre a cultura camponesa, seus valores e a manutenção da vida no campo.

Esse é um pequeno exemplo, mas cumpre a função de evidenciar que o conceito aqui trabalhado, embora tenha vínculo imediato às práticas educativas do MST, tem uma função e alcance mais amplo, pois articulam as instâncias citadas e debatidas, como concepção de Estado, modo de produção, público/privado, democracia e, sobretudo, sociedade. Esse alcance, a relação com a Educação do Campo e a compreensão do alargamento da ação da sociedade civil organizada, mesmo sobre esse Estado sob o capitalismo, pode ser constatado na orientação para trabalho para demandas do movimento, contida em documento recente do MST sobre a educação, em que é estimulada a prática de:

Ocupar espaços abertos à Educação do Campo nas secretarias de educação, universidades e outros órgãos para pautar a discussão sobre ampliação do acesso à educação aos trabalhadores do campo, sobre desenho pedagógico de escola, formação de educadores (...) (MST, 2008, p.15).

O exemplo da educação do campo é colocado com a finalidade de evidenciar o caráter amplo que a categoria ocupação da escola vem alçando. E ainda, a afirmação acima contém elementos cruciais, como a perspectiva de classe, do direito do acesso à educação para a classe trabalhadora, isso sem perder de vista a especificidade dos sujeitos do campo e de movimento social, tudo articulado à categoria ocupação. Contudo, o fato é que o ponto de partida da referida categoria é um movimento social. Daí, o próprio caráter educativo que o movimento social contém é uma referência necessária para as demais análises. Assim, a gênese da construção do sujeito político coletivo constituído nas lutas sociais específicas, como a reforma 
agrária e a luta de classes, em uma esfera mais ampla, é um dos pontos de partida para a presente análise.

A ação do MST é muito abrangente; trata-se de um movimento social de massas, que tem como objetivo principal a reforma agrária, mas têm frentes de atuação nas mais variadas instâncias, como a educação, a saúde, as relações de gênero, a produção cooperada e a agricultura orgânica e, ainda, a própria identidade Sem-Terra é de uma extensão bastante multidimensional. Como expõe Caldart:

Este sem-terra, formado pela dinâmica da luta pela Reforma Agrária, e do MST, pode ser entendido também como um novo sujeito sociocultural, ou seja, uma coletividade cujas ações cotidianas, ligadas a uma luta social concreta, estão produzindo elementos de um tipo de cultura que não corresponde aos padrões sociais e culturais hegemônicos na sociedade capitalista atual e, na brasileira em particular, inscrevendo-se no que poderíamos talvez chamar de um movimento sociocultural que reflete e prepara mudanças sociais mais profundas (CALDART, 2000, p.26).

Mesmo que restrita à questão educacional, essa diversidade de instâncias que envolvem a dinâmica organizacional do MST continua abrangente, pois há uma série de experiências educativas pesquisadas, oriundas do MST e outras em constante investigação. A tendência é a ampliação de tais estudos, uma vez que se intensificam as experiências educativas nesse Movimento, nas várias áreas: educação infantil, fundamental, média, de jovens e adultos, superior e pós-graduação em nível de especialização.

Sintetizando e articulando as duas esferas - a educação formal e a não formal - ao analisar a singularidade do MST como espaço formativo, Maria Antonia de Souza destaca:

No âmbito educacional, é possível apontar duas características centrais, a saber: a presença da luta pela escola pública no assentamento, portanto, o campo de educação formal e a presença de processos educativos não formais existentes desde a origem do movimento social. (SOUZA, 2006, p. 32. Grifos no original).

Dada à amplitude da temática - a educação no MST - é necessário delimitar o aspecto a ser observado. Em Martins (2004), a categoria ocupação da escola é identificada como aglutinadora de elementos capazes de estabelecer relações da práxis educacional do MST com a gestão democrática da escola. Porém, ao avançar na constituição e definição dessa ocupação da escola, percebe-se que seu alcance vai além de elementos de gestão escolar. Atinge elementos da organização do 
trabalho pedagógico, relação social da escola e até mesmo conteúdos escolares. Por esse motivo, advoga-se que ocupação da escola é uma categoria singular, a ser evidenciada e estabelecida no cenário educacional, pelo seu ineditismo e sua amplitude que suas dimensões adquirem e podem potencializar.

É necessário apontar que a presente categoria não está sendo construída nesse momento. A ocupação da escola é uma prática encontrada tanto nos documentos e cadernos de formação do MST, quanto nas teorizações acadêmicas de suas lideranças, como faz Roseli Salete Caldart, membro do Coletivo Nacional de Educação do MST, em sua tese de doutorado. Porém, mais que uma prática, ela é uma experiência política coletiva que oferece substrato material para ações, como a inserção da Educação do Campo na agenda oficial nacional. No sentido de evidenciar a essência original da ocupação da escola, recorro à teorização de Caldart. Ela atribui três significados à ocupação da escola:

Primeiro: as famílias sem-terra mobilizam-se pelo direito à escola e pela possibilidade de uma escola que tenha realmente sentido em suas vidas presente e futura (...)

Segundo: o MST, como organização social de massas, decidiu, pressionado pela mobilização das famílias e das professoras, tomar para si ou assumir a tarefa de organizar e articular por dentro de sua organicidade esta mobilização, de produzir uma proposta específica para as escolas conquistadas, e de formar educadores e educadoras capazes de trabalhar nesta perspectiva. (...)

Terceiro: através deste processo a que se referem as duas afirmações anteriores, o MST incorporou a escola em sua dinâmica (...) acampamento e assentamento do MST tem que ter escola; e a escola passou a ser vista como uma questão também política, quer dizer, como parte da estratégia de luta pela Reforma Agrária, vinculada às preocupações gerais do Movimento com a formação de seus sujeitos (CALDART, 2000, p.145-6. Grifos no original).

Essa categoria está presente também nos discursos de outras lideranças do Movimento e, ainda, há teóricos que refletem sobre a ocupação da escola, como Gentili (1998), Marquesini (2004) e Martins (2004). A contribuição das experiências da ocupação da escola para a democratização das relações de gestão escolar pretende ser destacada á medida que contribua para as experiências do sistema de ensino enquanto totalidade. O que se faz articulado com a referência material localizada na práxis do MST é uma articulação ousada e difícil de ser empreendida, dada às particularidades que envolvem o fenômeno educacional no interior de um movimento social. Contudo, é justamente essa particularidade o objeto a ser delineado se relacionando com a universalidade. 
Em um primeiro momento, pode-se destacar a concepção de "público" contida na ação e necessária para a gestão da escola, uma perspectiva de que o público é um bem pertencente à população. Desse modo, o proprietário da escola não é o Estado como um ente estranho à comunidade, mas, sim, a comunidade, que tem no Estado um elemento provedor de seus diretos sociais. Isso se articula ao primeiro significado que Caldart atribui à ocupação da escola. Seja no acampamento, seja no assentamento, a escola que atenda e esteja junto aos Sem Terra é um direito como qualquer outro direito do cidadão. E é por aqui que se inicia o processo de ocupação, uma vez que tal escola, além de não existir, é conquistada somente com muita luta dos sujeitos sociais envolvidos.

A regra geral, desde o acampamento, é fazer valer o direito à educação como uma luta diária, desde a construção efetiva e literal da escola, até o reconhecimento do poder público. Como ponto de referência material, pode-se ilustrar tais dificuldades e desafios, com a experiência da escola que é campo empírico deste trabalho. Ao reconstruir a história coletiva da Escola Chico Mendes, a educadora e militante do MST, Maria Edi da Silva Comilo (2008), aponta para a trajetória árdua da escola, iniciada com as "escolas de emergência". Estas foram construídas com lonas, quando não, sob as mangueiras, alunos escrevendo com papelão e carvão; história de despejos e reconstruções, enfrentamentos e reivindicações, manifestações e ocupações, até que, aos poucos, os sem terra vão "arrancando" a escola do Estado. Ao refletir sobre toda a trajetória que marca a ocupação da escola Chico Mendes, Comilo (2008) sinaliza, com considerações sobre o significado dessa ocupação para o movimento, da seguinte maneira:

Para nós, do MST, é necessária a ocupação dos muitos latifúndios existentes na sociedade capitalista. A ocupação da terra é a necessidade mais gritante, porém, a educação também é passível de ser ocupada pelo movimento, e esse é nosso intuito. Ocupar a escola não se esgota na conquista de um espaço consolidado legalmente, ou mesmo confortável, com salas de aula substituindo o espaço dos barracos; ocupar a escola incide sobre as relações escolares e, por conseguinte, sobre a formação humana que se proporciona (COMILO, 2000, p.19).

Aqui pode ser inserido o segundo aspecto definido por Caldart para a ocupação da escola. Essa incidência sobre as "relações escolares" é uma das exigências que o MST impõe para fazer uma escola "com sua cara", com propostas específicas voltadas para sua realidade e objetivos sociais, como são, por exemplo, os vários cursos técnicos em agroecologia, administração de cooperativas, saúde, formação de professores. E, para formar seus educadores, há parcerias com universidades, com a "Pedagogia da Terra", as ações pedagógicas voltadas para o 
desenvolvimento do campo e a formação política que se associa a uma perspectiva de sociedade que supere a organização societal vigente.

Pode-se ainda atentar para elementos "metodológicos" como a pedagogia da alternância ${ }^{4}$, a organização curricular por temas geradores. Ou formas escolares, como a Escola Itinerante ${ }^{5}$. Ou seja, uma vez que "todo projeto pedagógico é político e se acha molhado de ideologia, a questão é a favor de quê e de quem, contra quê e contra quem se faz a política de que a educação jamais prescinde" (FREIRE, 1995, p.44-45). Nesse caso, é necessário se fazer a escola de acordo com o projeto de sociedade no qual tenham lugar central as camadas populares, pois, não existem conteúdos neutros, alfabetização natural, ou qualquer elemento escolar desprovido de intencionalidade política. E qualquer escola necessitaria inserir essa premissa no interior de suas práticas pedagógicas. Enfim, são dois momentos que podem ser ainda mais sublinhados no processo de ocupação da escola, o que Caldart chama de "significados" bastante definidos, primeiramente, o direito à educação propriamente dita e, na sequência, sua necessária transformação dispostos da seguinte maneira pela autora:

Nesse sentido, a expressão ocupar a escola constitui-se de dois significados fundamentais. Se é preciso ocupá-la é porque, tal como a terra de que foram arrancados, a escola também é um direito negado aos sem-terra, pela sua própria condição de trabalhadores do campo em uma sociedade cujo modelo de desenvolvimento pôde prescindir da escolarização do povo, especialmente deste que vive e trabalha no meio rural. (...) O segundo significado diz respeito à resistência e à produção no território ocupado. À medida que não foi pensada para ser ocupada por um tipo de população como a dos sem-terra, a escola de modo geral não se encontra preparada para recebê-los e, muito menos, para atender aquela demanda de estudo e formação que justificaram esta decisão de ocupá-la. Daí que esta ocupação implique também em um processo de transformação da escola, de modo a produzir nela uma proposta de educação que esteja em sintonia com os seus novos sujeitos (CALDART, 2000, p.139).

Por fim, o último aspecto que afirma a inclusão da escola na dinâmica de luta do MST, pode ser interpretado de outra maneira: a escola que incorpora a dinâmica

\footnotetext{
${ }^{4} \mathrm{O}$ regime de alternância pressupõe a articulação entre dois tempos educativos, o Tempo Escola, que são as atividades educacionais convencionais, realizadas na instituição de ensino, em sala de aula. E o Tempo Comunidade, que se faz em campo, geralmente na comunidade de origem dos educandos(as) com a implementação prática dos saberes escolares, em suas realidades. Mais detalhes em Ribeiro (2008).

${ }^{5}$ A Escola Itinerante é uma organização escolar que acompanha o processo de acampamento do MST, que pode ser transitória, uma vez que os integrantes estão sujeitos a desocupações e a necessidade de mudança de local. Essa forma escolar é reconhecida por sistemas estaduais de ensino. Mais detalhamentos em Camini (2009).
} 
do movimento. Como afirma a tese de Caldart, a Escola é mais que escola. Ou seja, incorpora elementos da construção do sujeito sociocultural em sua dinâmica de funcionamento, incorpora a formação em movimento, assim "a trajetória histórica de ocupação da escola confunde-se com a trajetória histórica de constituição e desenvolvimento do próprio MST (...)" (MACHADO, 2003, p.28).

De gênese das práticas educativas a uma práxis pedagógica, a ocupação da escola é essencial na ação educativa do MST. Tanto que nas deliberações, reflexões e direcionamentos atuais (MST, 2008), pode-se notar a centralidade que a ocupação da escola assume no debate. Ao fazer essa referência, abstraem-se dois desdobramentos; o primeiro reside na exposição de uma espécie de "balanço" que o movimento efetua sobre as dimensões que a ocupação da escola assume a partir das experiências educacionais em seu interior.

As dimensões que têm se destacado em nossas experiências de ocupação da escola são as seguintes: Formas organizativas: explicitadas e tornadas objeto do projeto educativo (...) trabalho na escola (...), a realidade como base do estudo ou do trabalho pedagógico com o conhecimento (...), inserção da escola (de seus sujeitos) nas lutas sociais e suas organizações coletivas (...), trabalhar diferentes dimensões do desenvolvimento humano integral (MST, 2008, p.12-4).

O outro desdobramento reside na clareza que esse movimento social detém do processo de articulação de sua prática educativa local e o processo de formação emancipatório social. As dimensões destacadas acima, bem como todas as reflexões acerca da ocupação da escola no documento citado, referem-se pontualmente às práticas educativas, em grande maioria, ligadas às práticas escolares em áreas de acampamentos e assentamentos. O que não impede o MST de ratificar o princípio que ocupar a escola é componente de um processo emancipatório social, que vai muito além da escola,

ou seja, enquanto organização coletiva o MST está reafirmando sua tarefa de ocupar a escola e ocupar-se dela e de seu processo educativo específico, enfrentando as contradições e as disputas que envolvem a instituição escolar em uma sociedade capitalista como a nossa e, particularmente, no momento atual de acirramento da luta de classes de que participamos (MST, 2008, p.01).

Essa relação entre a prática educativa local, específica, "a realidade como base", com uma dimensão social, mais que isso, com um projeto societal é, categoricamente, a característica educativa mais contundente e "eficaz" da práxis do 
MST e, consequentemente, da ocupação da escola. Elemento constante quando das primeiras elaborações sobre essa categoria no MST e, como assinalado, no documento mais recente do movimento, o que indica a centralidade da ocupação da escola para o MST.

\section{CONSIDERAÇÕES AO FIM}

De modo geral, várias características da ocupação da escola do MST podem ser encontradas em outras experiências de ocupação da escola, seja nas práticas de trabalhadores urbanos na busca da educação para seus filhos, seja ainda nas práticas realizadas pelos estudantes brasileiros nos últimos dois anos, ou ainda, as mesmas práticas realizadas em outros países. Proceder às universalizações com 0 contexto educacional em geral, ou seja, definir a ocupação da escola enquanto categoria, sem antes atentar para sua vinculação à prática educativa do MST seria, no mínimo, uma displicência acadêmica, intelectual e política.

É perfeitamente compreensível que as demais práticas de ocupação das escolas, distintas, tenham elementos singulares, trajetórias e antecedentes históricos próprios. Contudo, como se pode ver com o artigo exposto, há muitos pontos de convergências, que permitem tomar a ocupação como categoria, em modo amplo, e também, em modo particular, para o fenômeno educativo, pois é nos processos de aprendizado que residem muitas das características comuns de processos distintos.

De modo geral, a garantia ao direito e, em particular, o direito à educação é central nos processos de ocupação. Seja para a concentração em uma área rural de acampamento; ou para o conjunto de estudantes urbanos que terão sua escola fechada pela reorganização do sistema educativo, ocupa-se para ter acesso ao direito à educação. Também é derivado desse processo a formação de uma identidade coletiva entre estudantes, comunidade, equipe de trabalhadores da escola, o que gera processos educativos, formais e não-formais, horizontais, observando e praticando o princípio de gestão democrática do processo educacional.

Esses aprendizados se fazem ainda mais necessários nos tempos atuais, pois a democracia como elemento formativo é central nos processos de ocupação das escolas, onde quer que ocorram. Em tempos de ausência de democracia no Brasil, em tempos de intolerância e totalitarismos, práticas que intensifiquem o diálogo, a coletividade e a reflexão crítica, sobretudo a contestação às imposições é um alento, uma centelha de esperança para os processos formativos escolares.

\section{REFERÊNCIAS BibLIOGRÁfICAS}

CALDART, Roseli Salete. Pedagogia do Movimento Sem Terra. Petrópolis: Vozes, 2000.

COMILO, Maria Edi da Silva. A construção coletiva da Escola: A Escola Chico Mendes e sua história. In: MARTINS, Fernando José (org.) Educação do Campo e formação 
DOI: $10.12957 /$ e-mosaicos.2017.30293

continuada de professores. Campo Mourão; Porto Alegre: Editora FECILCAM; EST. 2008. p.11-29.

FERNANDES, Bernardo Mançano. A Formação do MST no Brasil. Petrópolis: Vozes, 2000.

FREIRE, Paulo. A Educação na Cidade. São Paulo: Cortez, 1995.

GENTILI, Pablo. Ocupar a terra, ocupar as escolas: dez questões e uma história sobre a educação e os movimentos sociais na virada do século. In: . $A$

Falsificação do Consenso. Simulacro e imposição na reforma educacional do neoliberalismo. Petrópolis: Vozes, 1998. p.117-130.

MACHADO, Ilma Ferreira. A Organização do Trabalho Pedagógico em uma Escola do MST e a perspectiva da formação omnilateral. Campinas: Unicamp, 2003. 325 f. Tese (Doutorado em Educação) Programa de Pós-Graduação em Educação. Faculdade de Educação. Universidade Estadual de Campinas, 2003.

MARQUESINI, Jocilene Mongim. Ocupando a escola: uma cartografia das práticas educativas escolares do movimento dos trabalhadores rurais sem terra. Vitória: UFES, 2004. 142 f. - Dissertação (Mestrado em Educação - Programa de PósGraduação em Educação. Centro de Educação. Universidade Federal do Espírito Santo. 2004.

MARTINS, Fernando José. Gestão Democrática e Ocupação da Escola: o MST e a Educação. Porto Alegre: EST, 2004.

2011.

. Ocupação da Escola: uma categoria em construção. Cascavel: Edunioeste,

MST. Dossiê MST Escola - Documentos e Estudos 1990-2001. Caderno de Educação. n. 13 - edição especial, Veranópolis: Iterra, 2005.

. Educação no Documento Básico do MST. In: . Dossiê MST EscolaDocumentos e Estudos 1990-2001. Caderno de Educação. n. 13 - edição especial, Veranópolis: Iterra, 2005. p.29-30.

. O MST e a Escola. Documento elaborado a partir de Seminário realizado em Junho de 2008. Texto Mimeo. 17p.

PARO, Vitor Henrique. Gestão Democrática da Escola Pública. São Paulo: Ática, 1997.

SOUZA, Maria Antonia de. Educação do Campo: propostas e práticas pedagógicas do MST. Petrópolis: Vozes, 2006. 